\title{
Research on Electrical Fires: The State of the Art
}

\author{
VYTENIS BABRAUSKAS \\ Fire Science and Technology Inc. \\ $9000-300^{\text {th }}$ Place SE \\ Issaquah, WA 98027, USA
}

\begin{abstract}
Electrical fires - fires directly caused by the flow of electric current or by static electricity - are one of the important types of structure fires. The subsequent development of an electrical fire is generally no different than that of any other type of structural fire. But the mechanisms leading to ignition of an electrical fire are, in many cases, uniquely specialized and in need of specific research to delineate their characteristics. Despite the importance of electrical fires, there has not been any institution in the English-speaking world with a long-term commitment to research in this area. Worldwide, the situation has been much better, due to extensive research in Japan. But most of this body of work was only published in the Japanese language and, consequently, had been unavailable to most scientists and engineers in English-language countries. The publication of the Ignition Handbook presented for the first time in English many of the salient Japanese research results in this field and these, taken together with the scattered studies that have been reported in English, allow a basic understanding of physical mechanisms to be reached. The present review presents the highlights of these findings. The review of the state of the art also shows that there are still a number of gaps where even first-cut research is not available. It is urged that a systematic research effort on electrical fires be established in the US and certain high-priority topics are outlined.
\end{abstract}

KEYWORDS: electrical fires, electrotechnical devices, fire investigation, forensic science, ignition sources, wiring.

\section{INTRODUCTION}

First, it is necessary to explain what an "electrical fire" is. It is not simply a fire originating in a device powered by electricity. If this were the case, then a fire caused by overheating cooking oil on an electric hob would be an electrical fire, which it is not. Instead, an electrical fire is a fire directly caused by the flow of electric current or by static electricity. Next, one should get some measure of how important are such occurrences. Even at this simple level, we already encounter obstacles, if we want to examine the US statistics. The NFIRS/NFPA national statistical database does not have an overall category of "electrical fires," but it does provide classifications according to the "Factor contributing to ignition" and a different classification according to the type of device that led to the ignition. If all of the Factors that denote an electrical fire are aggregated, the results in Table 1 emerge [1]. This implies that $16 \%$ of the structure fires that are reported to fire departments are electrical fires.

The other way that the NFIRS/NFPA database classifies fires is according to the origin, i.e., the type of device where the fire originated. This requires a certain amount of interpretation. Most kinds of electrical equipment are not intended to provide heating and, if they become a source of heat for the ignition of fire, then this must be considered to be an electrical fire. But there are a few categories, e.g., cooking and heating equipment, that contain a purposive heating element. With such devices, not all fires originating from them are going to be "electrical fires"; instead, a certain fraction will occur simply due to combustibles getting directly ignited from the heating element. A classification according to device of origin is shown in Table 2 [3]. Two categories, cooking equipment and heating equipment, will include a major fraction of ignitions directly from their heating elements. Cooking equipment accounts for $19 \%$ of the total fires, and it was estimated that only $10 \%$ of these are electrical fires. Heating equipment accounts for $12.4 \%$ of the total fires and it was again estimated that only $10 \%$ of these are electrical fires. About $8 \%$ of "electrical distribution" fires are due to ignition from an overlamped fixture or due to "combustibles too close" [2], thus, the electrical distribution contribution in Table 2 was reduced by $8 \%$. In the "appliances" category, clothes dryer fires account for approximately $3.2 \%$ of the total fires, and it is roughly estimated that $3 / 4$ of these are non-electrical in nature, reducing the $6.9 \%$ total to $4.5 \%$. The most problematic is a category called "other equipment". This accounts for some $11.3 \%$ of the reported fires, but there is reason to believe that much of this entire category represents codings where the origin of the fire was not successfully determined [1]. If 
taken at face value, most "equipment" is electrical in nature and such fires would be expected to be predominantly electrical fires; however, if the category comprises mostly errors, then the fraction of electrical fires there could be vanishingly small. Furthermore, lightning strikes are not included in the tabulation by device type. Some $1.5 \%$ of the total fires are reported due to lightning strikes, so this number should be added to the listings by device. Thus, on the basis of tabulation by device type, in view of the spread associated with "other equipment," the fraction of fires that are electrical in nature will be $18 \%$ to $29 \%$. But since Table 1 indicates $16 \%$, most likely a value closer to $18 \%$ than to $29 \%$ is appropriate.

The fact that there are serious uncertainties in the statistics on electrical fires is not surprising, in view of how the national statistics are collected. There are many competent scientists and engineers who can, in many cases, accurately determine the mode of failure of an electrical device. But almost no such personnel are employed by fire departments, which are the institutions that provide the official statistics. To a nonspecialist, electricity is often mysterious and confusing, so all such national statistics should be viewed as only a very rough approximation of reality. Nonetheless, whether electrical fires account for $16 \%$ or $29 \%$ of the total structure fires, this is a significant component.

It is obvious that static electricity comprises only a minuscule fraction of the total and, for this reason, we will not discuss it in this paper. Static electricity, however, has been associated with some very serious explosions and flash fires in industry and agriculture, thus, it is assuredly of concern in some sectors.

Table 1. US fire statistics on electrical fire causes (average per annum, 2002-2005)

\begin{tabular}{|l|r|c|}
\hline Factor contributing to ignition in reported structure fires & \multicolumn{1}{|l|}{ Fires } & Percent \\
\hline unclassified electrical failure or malfunction & 36,300 & 7 \\
\hline unspecified short circuit arc & 21,400 & 4 \\
\hline short circuit arc from defective or worn insulation & 11,400 & 2 \\
\hline arc or spark from operating equipment & 4,000 & 1 \\
\hline arc from faulty contact or broken conductor & 3,600 & 1 \\
\hline short circuit arc from mechanical damage & 3,400 & 1 \\
\hline water caused short circuit arc & 1,600 & $<1$ \\
\hline fluorescent light ballast & 800 & $<1$ \\
\hline Total (All electrical failure or malfunction) & 82,500 & 16 \\
\hline
\end{tabular}

Table 2. US structure fires which originated in electrical devices

\begin{tabular}{|l|c|}
\hline Device of origin ${ }^{*}$ & \multicolumn{1}{c|}{ Percent } \\
\hline electrical distribution & 8.8 est. $\dagger$ \\
\hline appliances & 4.5 est. \\
\hline cooking equipment & 1.9 est. \\
\hline heating equipment (electrical) & 1.2 est. \\
\hline other equipment & 0 to 11.3 \\
\hline${ }^{*}$ Does not include lightning or static electricity, since these are not \\
specific devices; there are no reliable data on static electricity fires, \\
but overall statistics indicate that 1.5\% of structure fires are due to \\
lightning, although a certain fraction of these may already be \\
included in the electrical devices listed above. \\
$\dagger+$ 'Estimated' means corrections were applied, as described in the \\
text.
\end{tabular}

In view of the fact that electrical fires are a notable problem, it may be a surprise to some to learn that there has not been in the English-speaking world any institution that has had a concerted research effort in this area. In fact, none of the major fire safety research laboratories have ever had such a research program, with the exception of a short-lived effort at the US National Bureau of Standards (now, NIST) in the early 1970s. The Consumer Product Safety Commission (CPSC) and the Bureau of Alcohol, Tobacco, and Firearms (ATF) have done some research on electrical fires, but neither institution has published any papers in the scientific literature, although some highly specialized reports from CPSC have been made public. Elec- 
trical safety standards are mainly published by the Underwriters Laboratories Inc. (UL) in the US and by the International Electrotechnical Commission (IEC) internationally. These institutions have also published almost no research papers, and the implications of this are further discussed at the end of this paper.

The problem has been taken much more seriously in Japan, where the National Research Institute of Police Science has had a long-standing research program on electrical fires, while other Japanese laboratories and forensic institutes have also been active in the area. With very few exceptions, however, the Japanese research was not disseminated in English until the 2003 publication of this author's Ignition Handbook [3]. The latter comprised a major effort to collect all ignition-related material, and in the electrical fires area became the first treatise to undertake a comprehensive presentation of the Japanese research. The Handbook also collected research information on electrical fires from research institutions worldwide and became the first comprehensive repository of such information. In view of this, it becomes appropriate to consider the major areas where the state of the knowledge is already fairly advanced, and to contrast these with areas where research is fragmentary or poor. For the sake of brevity, the present paper does not include the primary-literature citations which are in the Japanese language; for readers needing these references, they can be found in [3].

Almost all of the published research on electrical fires concerns wiring in low-voltage applications, e.g., $100-240$ VAC circuits in residences and small commercial buildings. While electrical fault mechanisms in medium- and high-voltage circuits have been studied extensively in the electrical engineering literature, very few of these studies make any reference to the ignition potential from medium- and high-voltage installation faults (note that standards [4] define 'medium voltage' as encompassing $601 \mathrm{~V}$ to $15 \mathrm{kV}$, and 'high voltage' as being above $15 \mathrm{kV}$ ). Consequently, the predominant emphasis in this paper is on fires in $100-240$ VAC circuits, due to the paucity of information in higher-voltage applications. Conversely, it may be noted that, while electrical failures and fires in medium- and high-voltage installations may be spectacular, they account for only a very small fraction of the total electrical fires and make an equally small contribution to fire deaths.

\section{THE PHYSICAL MECHANISMS FOR ELECTRICAL FIRES}

The statistics presented in Table 2 are not particularly helpful in understanding the physics of electrical fires, since the type of device that failed does not in itself tell us the nature of the failure. Table 1 is organized ostensibly according to the mechanism of failure. But since almost none of the fire department reporting is done by personnel having an electrical science background, relying on these data is not appropriate. Instead, it is necessary to focus on whatever information can be gleaned from technical specialists in the field. Here, we will want to look at these incidents in two different ways: (1) according to nature of the physical mechanism that led to ignition; and (2) according to causative factors which caused the failure mechanism to be provoked.

The layman usually envisions only two mechanisms for electrical fires-short-circuits and overloads, but the actual situation is quite different. Concerning physical mechanisms, based on this author's experience and discussions with numerous practicing forensic and electrical engineers, a picture emerges (Table 3). Concerning the layman's view, we may note two things: overload is important, but not one of the top causes; and "short-circuits" does not correspond to a unique ignition mode. In fact, it can take the form of arcing in air, overload, or ejection of hot particles, and possibly some other mechanisms. In any case, shortcircuits are, again, not one of the top causes for electrical fires.

Table 3. Physical mechanisms causing electrical fires, ranked according to importance.

\begin{tabular}{|c|c|}
\hline Mechanism & Importance \\
\hline poor connections & \multirow{8}{*}{$\left.\right|_{\text {least }} ^{\text {most }}$} \\
\hline arcing across a carbonized path & \\
\hline arcing in air & \\
\hline excessive thermal insulation & \\
\hline overload & \\
\hline ejection of hot particles & \\
\hline dielectric breakdown in solid or liquid insulators & \\
\hline miscellaneous phenomena & \\
\hline
\end{tabular}




\section{Poor connections}

It is generally felt within the profession that poor connections (overheating or glowing connections) is the single most important mechanism for electrical fires. There will be numerous electrical connections encountered in the circuit feeding any end-use device and the device itself may also contain many connections. Each one, if badly made, may fail, and failure may lead to ignition, depending on the nature of the nearby combustibles. A glowing connection is an extreme case of an overheating connection, whereby the contact between two mating metallic surfaces is so poor that glowing is actually seen (Fig. 1). Temperatures of a glowing connection can exceed $1200^{\circ} \mathrm{C}$ [3]. The latter is, of course, above the melting point of pure copper; what is happening here is that the highest temperature occurs on one of the copper oxides that gets formed, rather than on the original metallic copper.

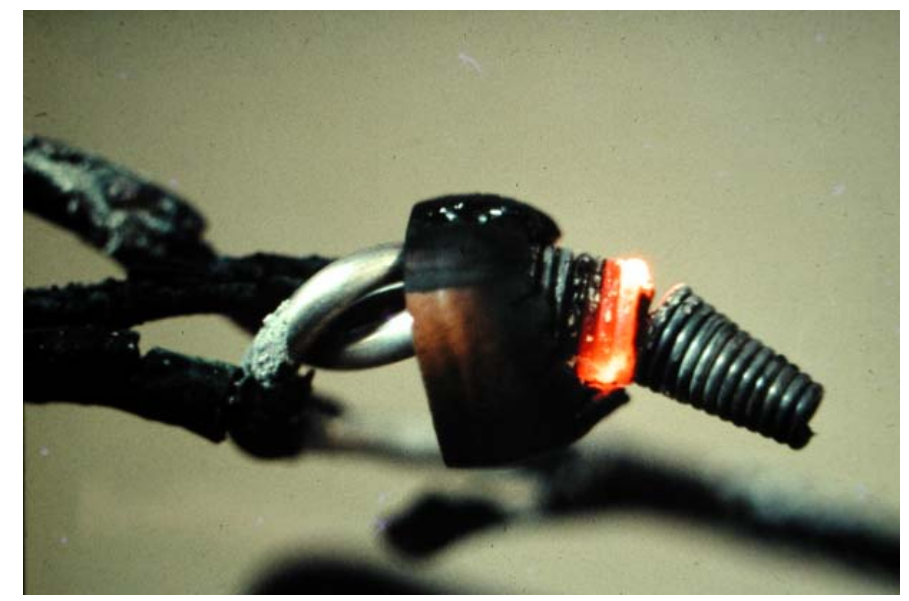

Fig. 1. Failure of a twist-on connector due to insufficient tightening; note that the plastic outer insulator of the connector has nearly melted away and only a small shoulder remains, allowing the internal helical spring to be exposed (Photo: Jesse Aronstein).

As a subcategory of poor connections, Japanese researchers documented a fascinating " $\mathrm{Cu}_{2} \mathrm{O}$ breeding process" [5,6], whereby the copper itself stays at a relatively low temperature, but the oxide that is created glows brightly and meanders in a snake-like fashion (Fig. 2). Neither glowing nor $\mathrm{Cu}_{2} \mathrm{O}$ breeding are necessary, however, for a connection to be bad, overheat, and lead to fire. In domestic branch circuit wiring, the power levels [3,6] involved in an overheating connection are not high - typically 10 to $50 \mathrm{~W}$-but, when concentrated on a small area, this can suffice to ignite combustibles. A heavy current draw is not required in order to have a glowing connection; these have been noted under loads as low as $0.3 \mathrm{~A}$ in a $120-\mathrm{V}$ circuit.

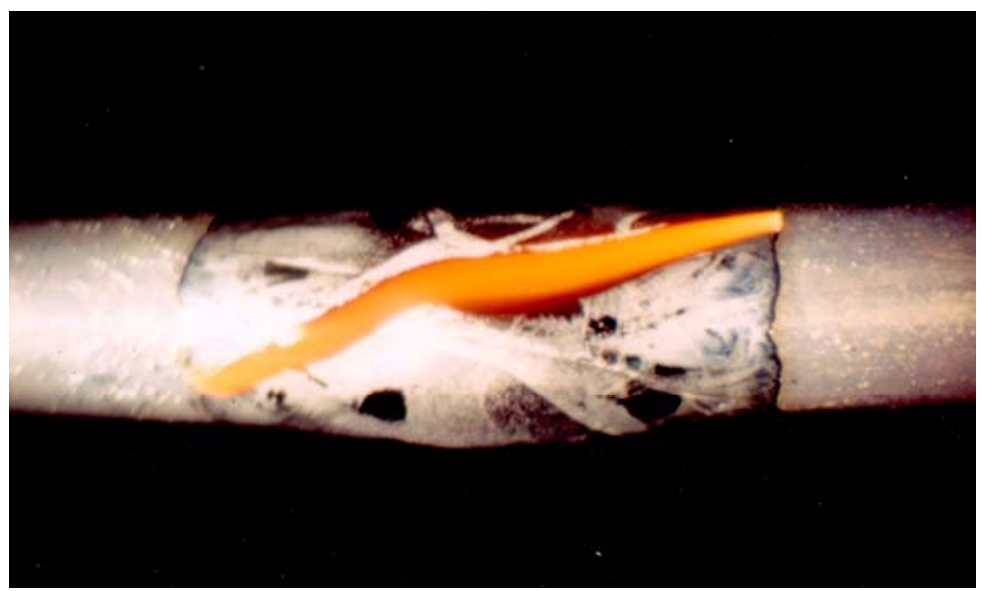

Fig. 2. The $\mathrm{Cu}_{2} \mathrm{O}$ breeding process (Photo: Yasuaki Hagimoto). 
In some cases, a bad connection is made when a connection is not intended at all. Most commonly, this happens when a nail or a staple pierces a conductor. In most parts of North America and in many other countries, it is permissible to install house wiring using cables which are plastic-sheathed and lack any metallic outer protection. This type of wiring is notably prone to such accidents, although these accidents are less common than might be surmised. In such a fault, when the nail or staple pierces a conductor, there arise two bad connections - copper to steel, and steel to copper. Fig. 3 shows a laboratory recreation of such a fault.

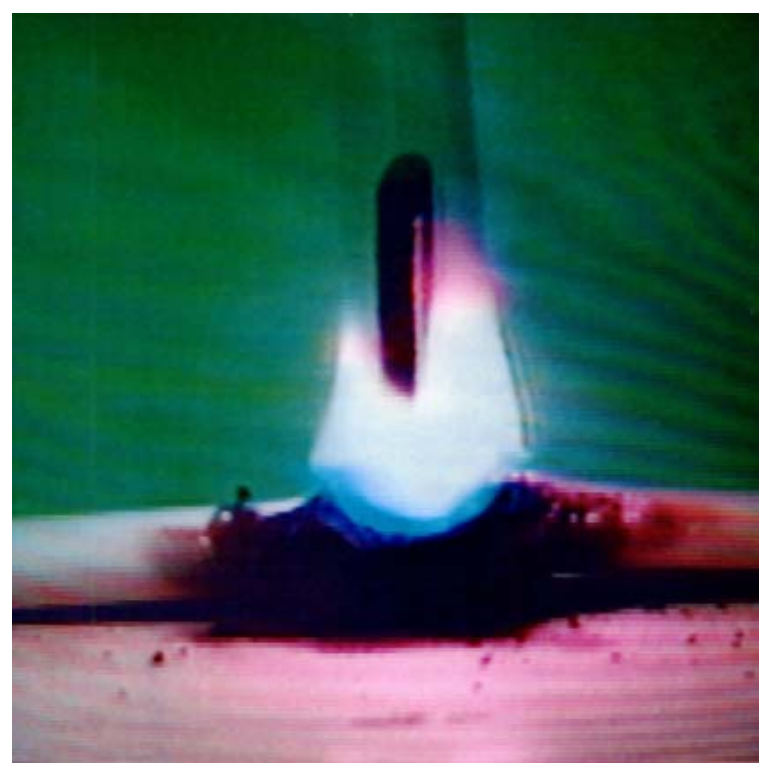

Fig. 3. A laboratory recreation of a poor connection resulting when a staple pierces and bifurcates a current-carrying conductor (Photo: Richard Brugger).

Part of the reason that poor connections are such a serious problem is that they are hard to detect. Provided that more than a minuscule amount of current is being carried, the voltage drop across a glowing connection is low, generally around $2-5 \mathrm{~V}$, and this will be hard to detect. By the way, glowing connections, examined in detail, are a non-ohmic circuit element and the voltage drop across it decreases as the current increases (an ohmic device has the characteristic that the voltage drop across it increases directly proportional to the current flow).

Amateurs doing electrical wiring are a notorious cause of poor connections, but defective design or manufacture are also common. For a few years around the early 1970s, aluminum branch wiring was being propounded in the US. Due to a host of metallurgical reasons, it turned out to be almost impossible to make reliable connections with such wiring (the problem does not affect large-diameter aluminum conductors used for service mains, etc.). This is one of the few areas where there has been copious US laboratory research. CPSC sponsored projects at NBS (now, NIST) and at several other institutions and details have been compiled in [3]. Fortunately, early alarm was raised about the very serious fire-causing potential of such connections and the aluminum-wiring practice stopped in the late-1970s.

'Back-wired, push-in' receptacles are another category of product where there is a strong propensity for reliable connections not to be made. Similarly, many appliance fires result due to a bad connection at a 'push-on' connector (Fig. 4). These connectors have been widely used as an economical manufacturing technique, since they require neither soldering nor screw fastening. But they can fail due to inadequate force between the male and female portions. Many of these are assembled by being crimped onto the end of a wire, and the crimp itself can also form a bad connection; this typically occurs due to worn-out or out-ofadjustment crimping machinery.

After a fire, the presence of a poor connection is normally established by noting anomalies in corrosion. Corrosion on copper, brass, and similar surfaces is temperature dependent, thus a poor connection will tend to accumulate significant corrosion, while a good one will not, assuming the environment is not so extremely harsh as to attack all copper. Fire also creates high temperatures, but fire temperatures will tend to 
be relatively similar in any small volume within an appliance. Thus, if one connection shows a high degree of corrosion, while nearby connections do not, there is reason to investigate the corroded connection as a potential cause of the fire (Fig. 4). This topic would appear to be rich in possibilities for experimental study, but research has been surprisingly scarce.

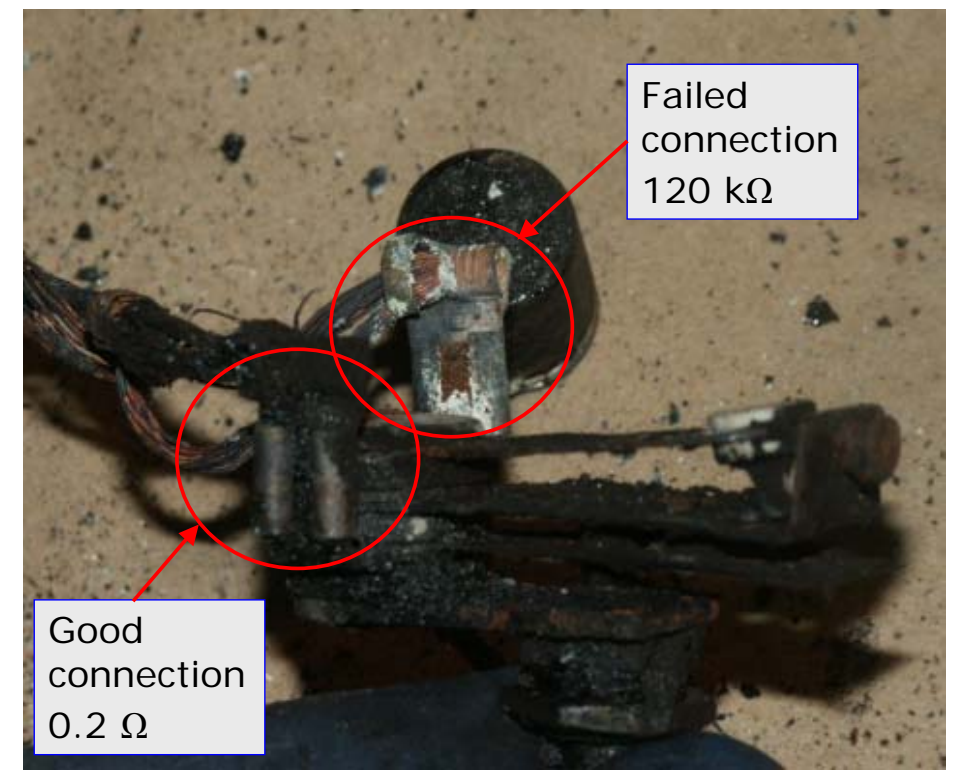

Fig. 4. Corrosion used as an indicator of a failed connection after a fire; the fire originated at a thermostat's failed push-on connector (Photo: Vytenis Babrauskas).

\section{Arcing across a carbonized path}

Arcing across a carbonized path is often considered synonymous with "arc tracking," although strictly speaking the latter has narrower scope and refers only to a carbonized path self-created by the flow of electrical current. Carbonized paths may also be created by external means, e.g., heating imposed from an external heat source upon the material. In the extreme case, a fire impinging upon electrical insulation may carbonize it. In any case, arcing across a carbonized path is a mechanism which is a common cause of fires, but which has received inadequate study. The mechanism has been known for a long time- a German textbook [7] discussed it in 1937, and an ASTM standard was already published in 1948 [8]. But, despite this history, the literature does not explain the mechanism in many aspects. Arcing across a carbonized path is typically subdivided into two types: wet tracking and dry tracking. Wet tracking may occur if a wet, polluted (wet tracking does not occur if the water is distilled) path can be formed across an insulator, spanning from one conductor, to a conductor at a different potential. Dry tracking is less common and involves the formation of a carbonized path in the absence of moisture. The standard test for this propensity involves applying an electrical arc across the surface of the insulator to determine how readily such a path may be formed.

It is generally known that surface-arcing electrical discharges, known as scintillations, are low-temperature, low-energy events. But if the process continues unhindered, full-fledged arcing in air between two conductors may be end result, and the latter will show high temperatures and may be quite destructive. Much of the published research has been conducted using standardized International Electrotechnical Commission (IEC) or ASTM tests $[9,10]$ tests. Unfortunately, what occurs in these tests has almost no relation to performance of real cables [14] and the tests, especially IEC 60112 [9], are misleading. Fig. 5 shows that PVC-insulated cables readily exhibit wet tracking with only 100 VAC impressed across the line, although the IEC 60112 test gives highly optimistic results for this material.

Perhaps the most unusual electrical phenomenon identified by Japanese researchers has been the propensity for PVC-insulated devices to fail by means of self-induced wet-tracking, while located in an atmosphere which is at very low humidity [14]. This is due to the fact that calcium carbonate is almost universally used as a filler in wire and cable grades of PVC. When exposed to moderate temperatures $\left(115-120^{\circ} \mathrm{C}\right.$ in longterm exposures, $165^{\circ} \mathrm{C}$ in short-term exposures), calcium chloride $\left(\mathrm{CaCl}_{2}\right)$ is produced as a reaction product 
between PVC and calcium carbonate. It is highly hygroscopic and attracts moisture so strongly that a moisture film can form along the surface. This film will be particularly prone to arc-tracking since $\mathrm{HCl}$ is also liberated as PVC is thermally degraded. Wet-tracking failure can then result (Fig. 6).

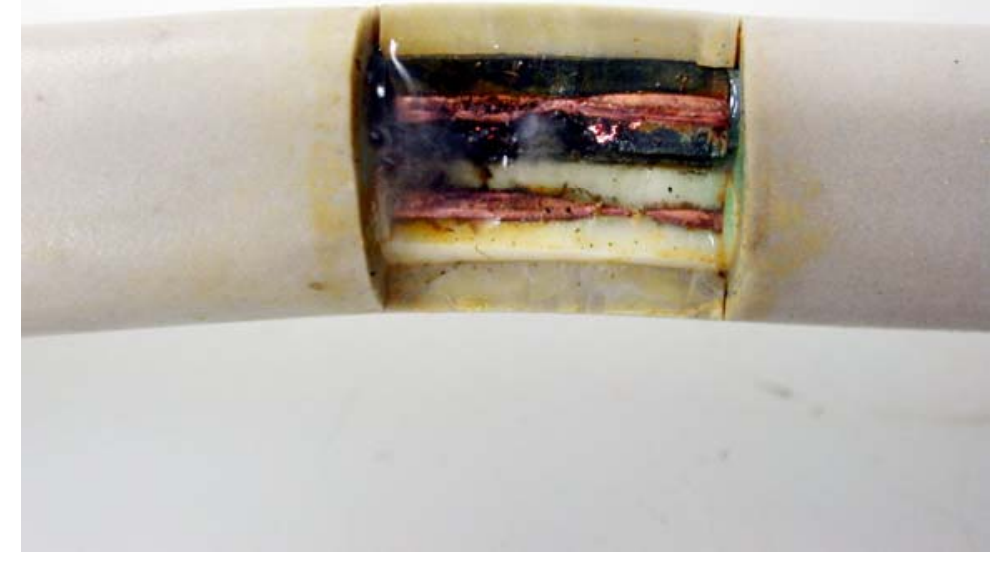

Fig. 5. Wet arc tracking in a Japanese PVC-insulated, PVC-sheathed electrical cable with 100 VAC impressed voltage (Photo: Yasuaki Hagimoto).

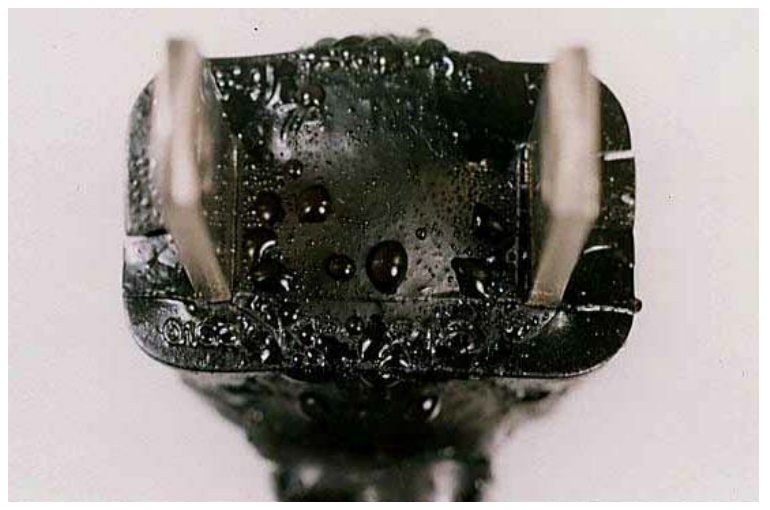

Fig. 6. Failure of a PVC plug due to self-induced wet tracking (Photo: Kiyomi Ashizawa).

It is often assumed that, if very small arc beads are found on wiring, this indicates that arc tracking occurred (as opposed to direct shorting). But there has been no study to examine the outcomes of arcing on real cables, i.e., to relate the metallurgical damage to this particular failure mechanism. Several authors have written papers describing minimum current values needed to cause arc tracking in a particular type of plastic [3]. But their values are exceedingly different and it is unknown how test conditions affect this outcome. A question which is sometimes asked is whether there is a minimum power limit, below which arc tracking for a particular plastic would be precluded. But, again, the literature is not helpful on this point. Plastics differ in their propensity to arc tracking. To arc track, the material must be capable of charring. Thus, thermoset plastics, aromatic polymers, or those containing alternating double bonds are known to be more prone. But no plastic, not even such "melting" polymers as polyethylene, is totally resistant to arc tracking. A number of the standard test methods assign a voltage to a particular material, below which it is considered that arc-tracking will either not occur, or be very limited. These values are typically in the hundreds of volts, yet, in actuality, arc-tracking has been a serious problem in the automotive industry, where voltages are vastly lower than these test classifications envisage (Fig. 7).

Arcing across a carbonized path must be distinguished from what electrical engineers call 'surface flashover.' This term has nothing to do with room flashover, as known in fire science. Instead, it refers to an 
process whereby there is arcing along the surface of a material which is a poor insulator, i.e., an insulator of not particularly high resistivity. This is generally of concern only in medium- or high-voltage installations.

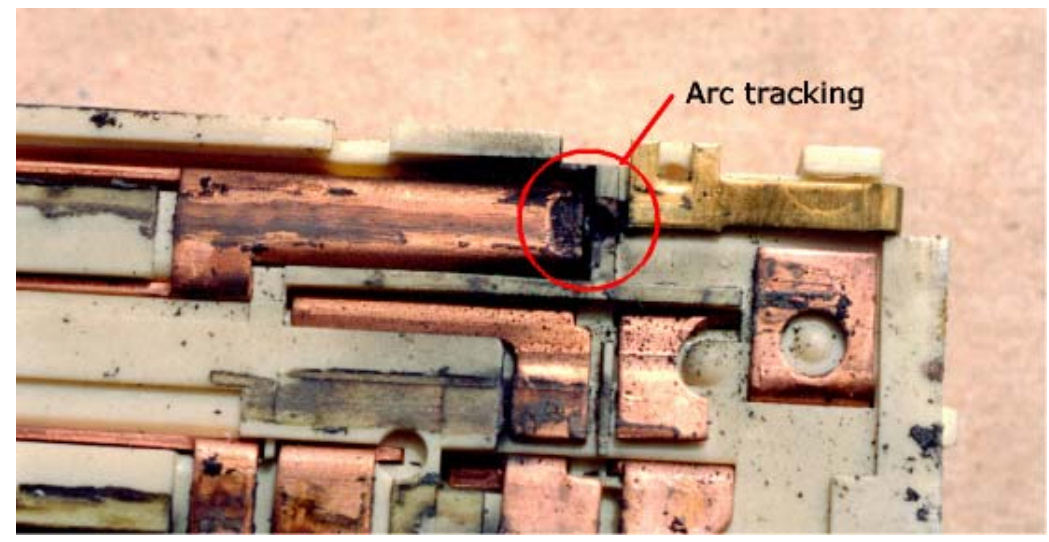

Fig. 7. Arc tracking failure of an automotive ignition switch, in nominal 12 VDC service (Photo: Chris Bloom).

\section{Arcing in air}

It is very easy to ignite materials, especially "tinder" type fuels, with arcing in air. However, when considering circuits of $240 \mathrm{~V}$ or lower, arcing in air is often the end result of another mechanism and not an independent event. With stationary electrodes, $240 \mathrm{~V}$ (rms) will not lead to arcing, since it corresponds to the Paschen limit value ( $340 \mathrm{~V}$ peak $=240 \mathrm{~V} \mathrm{rms}$ ). It is readily possible to cause arcing in circuits as low as a few volts, however, by opening up the circuit, i.e., causing a "break arc." Such an opening of a circuit can occur because someone or something shorted two conductors together. Both due to the action of the magnetic field and due to heating and ejection of metal when this happens, conductors shorted together will tend to separate, at which point an arc can be expected. But arcing in air can also occur due to a poor connection opening up or as the end result of arc tracking.

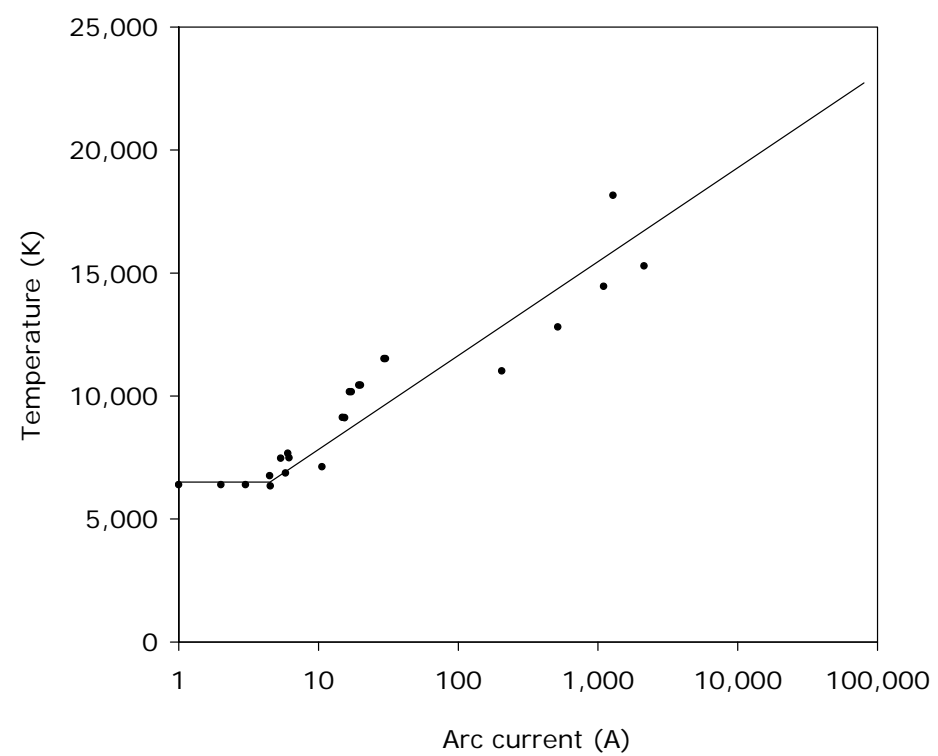

Fig. 8. Arc temperature as a function of current.

Arc temperatures are around $6500 \mathrm{~K}$ at the lowest possible current for arcing, and rise progressively to tens of thousands Kelvins for high currents (Fig. 8) [3]. Now, $6500 \mathrm{~K}$ is above the ignition of any ignitable substance. But this does not mean that if an arc impinges against such a substance, it will ignite. Reasons for non-ignition are at least two: (1) a solid object extracts heat from an arc, and the arc may extinguish if a 
solid is interspersed; (2) the material may get ablated so fast that it cannot ignite. It would be useful to have recourse to experimental studies examining non-ignitions from arcs, but no such studies exist.

\section{Overload and excessive thermal insulation}

These two factors can also be grouped into a more general factor of "currents exceeding the ampacity of the wire or cable." The temperature to which a wire or cable will rise due to flow of current depends on several factors, primarily on the construction of the wire/cable, the current flow, and the natural convection cooling available. The latter is sensitive to geometry and to any factor which may diminish natural convection, especially applying thermal insulation materials of any type. The safe carrying current capacity is termed "ampacity." Ampacity values are published in electrical codes and handbooks, but they are subject to misinterpretation and misapplication, since the value will change if the actual installation shows any convective cooling differences from the standardized conditions used to establish the handbook value. Short-term experiments show that, absent excessive thermal insulation, it takes a $300-700 \%$ overload to cause ignition [3]. This is a very high overload and such overloads are not very common. Prolonged overheating, however, will cause progressive degradation of insulation, so smaller overloads may suffice to cause ignition, however, there have been no long-term experiments reported. It is much more common to find fires due to excessive thermal insulation. This is very likely because it is not intuitively obvious to the layman that a hazard is created by this means.

A concern was raised in recent years that the electrical code provisions in the US may be inadequate as regards bunched runs of NM-type cable within cavity-wall constructions. A forensic engineer spotted some construction sites where wiring installed in wall cavities, but not yet covered up with plasterboard, showed charring [11]. Upon running laboratory tests, it was found that $90^{\circ} \mathrm{C}-$ rated wiring, protected with circuit breakers of the correct size, can suffer overheating, if the maximum current permitted by the circuit breaker is sustained for several hours. If more than one cable run is bunched, or if thermal insulation is applied in the cavity, severe overheating will occur if large (but not large enough to trip the circuit breaker) loads are carried.

Overload is often thought of as simply an excessive load. But an overload condition can equally well occur if the load is normal, but the supply voltage becomes abnormally excessive. Factors causing the latter can include floating neutrals, lightning strikes, voltage surges, or a power supply of inappropriate waveform (harmonic distortion or harmonic overload).

A third way of creating an overload is due to stray currents. A stray current situation exists any time that current flow through an unintended path. By definition, an unintended path is not designed for any current to flow, thus, if current flow is excessive, a fire may result. One extreme example is the 'electrified house,' where metal siding, stucco mesh, or similar metallic components of a house become accidentally energized (Fig. 9).

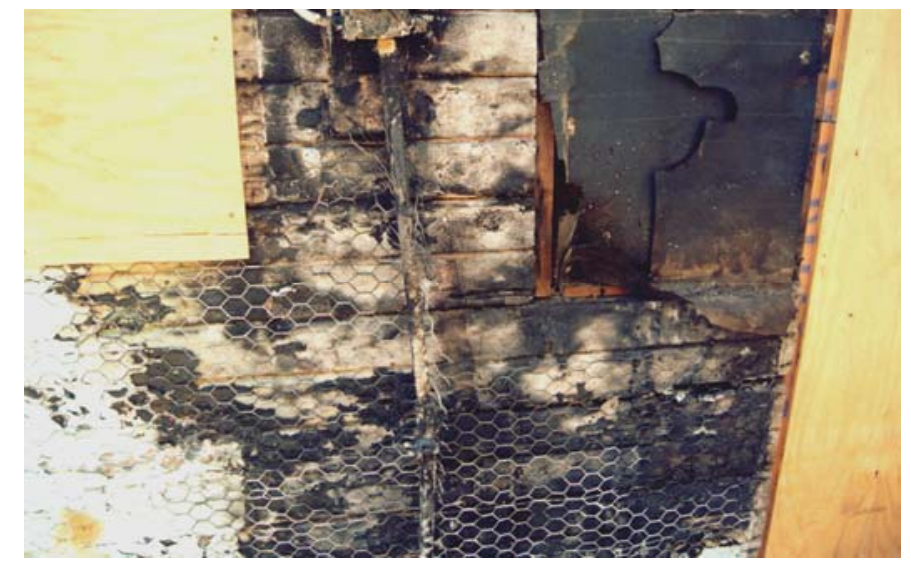

Fig. 9. Extensive burning of the exterior of a house which became electrified due electrical contact with the metal plastering mesh (Photo: Al Graps). 


\section{Ejection of hot particles}

Hot particles are commonly ejected when there is an overload so severe that conductors melt, e.g., a "short circuit." If the contact is poorly made (an "arcing short," rather than a "bolted short"), then melting is likely to be confined to the vicinity of the contact and particles (often termed "ejecta") may get ejected from there. Molten metal particles may ignite tinder-type materials and possibly other fuels (Fig. 10). These particles may be incandescent, but ignition is also possible from particles which are hot, but not incandescent. With the exception of one recent paper [12], this topic has received no significant laboratory study, although fires due to this cause are common. In some cases, ignitions due to ejecta are only secondary, since combustibles ignite in the direct vicinity of the original fault.

\section{Dielectric breakdown in solid or liquid insulators}

These mechanisms are a common cause of fires in high-voltage environments, but are less common in normal building wiring. Liquid insulators typically are used in high-voltage transformers, and dielectric breakdown can lead to a transformer explosion. Liquids (more precisely, gels) are also used as a dielectric in some capacitors and these may fail explosively, although research on this topic in notably absent. Solid dielectrics are most commonly some type of plastic. When used in low-voltage applications, there is usually a huge safety margin against dielectric breakdown, considering the intended circuit voltage. But fires do occur due to this cause from voltage surges, as discussed below. Fires also occur without large voltage surges when the thickness of the insulation becomes drastically too small. Typical cases involve creep when a cord or cable is greatly compressed under a mechanical load. This can be a cord placed under a heavy device, or an overdriven staple which does not puncture conductors but greatly compresses the insulation.

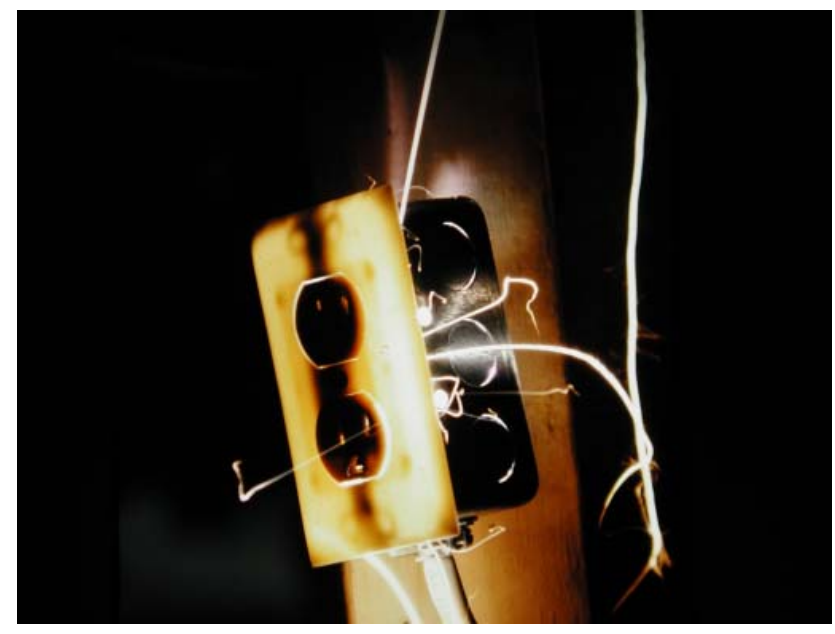

Fig. 10. Incandescent particles ejected from a faulty electrical outlet (Photo: Jesse Aronstein)

\section{Other mechanisms}

There is a plethora of additional mechanisms for ignition of fire from an electrical fault, but these tend to be less common. Such mechanisms include dendritic growth (now, becoming somewhat less rare in the automotive field), tin whiskers, adventitious batteries, and hydrogen explosions. The latter two mechanisms occur in wet environments. An electric current can be created if chemical conditions induce 'wet cell' action. If a DC circuit is already provided, and a wet environment impinges on it, electrolysis may generate $\mathrm{H}_{2}$, which can potentially accumulate and explode. The latter is not just a theoretical concern but an actual cause of fires, albeit rare.

\section{THE CAUSATIVE FACTORS FOR ELECTRICAL FIRES}

There are also no broad-based statistics on causative factors, but there have been a few limited ad hoc studies. A study by Hall et al. [2] examined the causative factor for 105 residential fires. CPSC [13] expanded the scope of this study and provided a summary of causative factors (Table 4); these studies, however, were limited to distribution systems in residential housing. When the causative factors are examined, it is seen that a large fraction involves activities which led to poor connections; also important — and simple to under- 
stand - are activities which led to overloads. The root cause in such cases tends to be incompetence of individuals installing, using, or modifying electrical equipment. But some causative factors emerge which need greater study, and we will focus on a few areas that are of special concern.

Table 4. Causative factors for electrical distribution systems fires, according to CPSC study.

\begin{tabular}{|l|c|}
\hline Factor leading to fire & Percent \\
\hline improper alterations & 30.4 \\
\hline improper initial installation & 16.6 \\
\hline deterioration due to aging & 13.8 \\
\hline improper use & 12.7 \\
\hline inadequate capacity & 12.2 \\
\hline faulty product & 9.4 \\
\hline unknown & 5.0 \\
\hline
\end{tabular}

\section{Physical damage}

Curiously, this factor is not even on the CPSC list, yet field experience suggests that this is a highly important causative factor. This is also an area where a number of Japanese studies have been published. Perhaps the most common cause of fire due to physical damage is the situation where abuse has been wreaked on the cord/male plug juncture. One of the means whereby this happens is if a plug gets repeatedly hit by a bedframe, table leg, or similar heavy object. A fire can result when sufficient strands have broken and now the last strand proceeds to break. Japanese researchers invented robotic cord-abuse testing equipment and also conducted some fundamental heat transfer studies in this area [3]. This is one of the very few physical damage mechanisms which has received substantial research attention. Yet, even this commendable research does not seem to fully address the realistic aspects of the case, since the laboratory studies have concluded that: (a) fire does not result until the very last strand breaks; (b) a current close to the rated ampacity of the cord must flow; and (c) thousands of bending cycles are needed to induce failure. Investigation of actual fires, however, suggests that the requirements for starting an electrical fire by this mechanism are nowhere nearly as rigorous as found in the laboratory studies. Apart from the last-strand problem, physical damage can be highly varied and there is no research at all on most other forms of damage.

\section{Voltage surges}

In his investigation of various fire incidents, the present author found numerous instances where none of the above causative factors seemed to play the decisive role. Instead, it was necessary to seek additional information. Wiring systems in residential and light commercial occupancies in North America predominantly use poly(vinyl chloride), PVC, as the insulation material. Thus, the question arose: Are there aspects of the dielectric breakdown of PVC which need to be understood to explain these fires? The result of this investigation was a recently (2006) published paper [14]; it is striking that this was the first-ever paper in the literature to endeavor to examine in detail the mechanisms of ignition of PVC-insulated wiring. Two important issues were documented in this study: (a) voltage surges (Fig. 11) are most likely responsible for a sizable fraction of otherwise-unexplained wiring fires; and (b) electrical-insulation grades of PVC have a surprisingly low actual failure temperature; the issue of temperature ratings is discussed below. Voltage surges can be a cause not only of failure of electronic equipment, but also of wiring. Wiring insulation is likely to fail at points of weakness, e.g., a manufacturing defect or a pinch point. But the PVC study revealed that the breakdown voltage vs. electrode gap distance relationship is known for PVC only for voltages in excess of $8 \mathrm{kV}$; for lower voltages - where the interest primarily lies - the relationship has not been characterized.

The PVC study also documented that electrotechnical standards of UL and the IEC lack adequate measures against ignition due to voltage surges. Voltages up to $6 \mathrm{kV}$ (peak) should be resisted, since voltages above this level cannot be protected against (because $6 \mathrm{kV}$ is the typical value [15] at which all of a building's wiring devices will fail). But the standards typically provide testing only up to $1400 \mathrm{~V}$, or thereabouts. The need to provide protection against surges up to $6 \mathrm{kV}$ was not a novel conclusion by the present author. Instead, the literature shows that Martzloff and Hahn already published this finding in a prominent electrical engineering journal in 1970 [16], but the standards institutions took no action. Furthermore, it turns out that, to be effective, surge testing has to encompass three types of waveforms, slow, medium, and fast-rise. But UL and IEC standards, again, do not provide for such testing. 


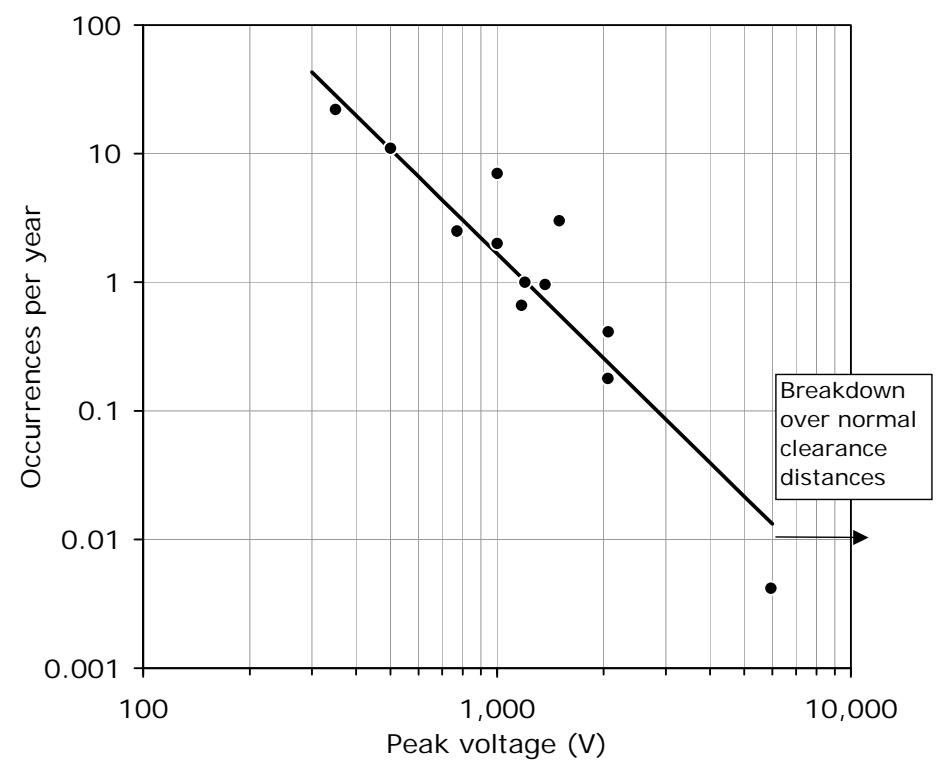

Fig. 11. Surge voltages experienced in branch-circuit wiring

\section{Temperature class of insulation and deterioration due to aging}

Electrical insulation is typically an organic polymer and, as such, will degrade with both time and temperature. Consequently, for a particular insulation material there will be a temperature beyond which it would not be safely operated. UL and IEC treat this by establishing temperature classes and assigning each insulation material to a particular temperature class, but there are three problems with the way that this is executed: (1) The class rating methodology is based on a 1948 paper [17] and has not been reexamined for more than half a century. (2) The UL methodology [18] allows classification by experience of "field performance" without any laboratory testing. When laboratory testing is done, emphasis is on the mechanical properties and, secondarily, dielectric strength; no performance measure is used that has a direct relationship to the ignition potential. (3) Data have been published [19] showing that the temperature ratings for PVC insulation are erroneous, and err in the unconservative direction. This situation means that there can be little confidence in the validity of the temperature ratings. To correct matters will require substantive research into failure temperatures and also development of realistic test methods for routine use.

The Fire Protection Research Foundation has taken an interest in this topic and has sponsored research studies and a recent conference [20]. Most of the work has been statistical in nature, or focused on managerial decisions, but UL did report some useful experimental data [21] on aged wiring extracted from actual houses. No appreciable age effect was found for wiring younger than about $30-40$ years. Older wiring, however often showed progressively worse dielectric breakdown characteristics and poorer mechanical properties. There was a major difference between thermoplastic and rubber-insulated wiring. A significant fraction of rubber-insulated wiring (typically installed prior to 1960) was generally in very bad shape and many specimens were crumbling or otherwise mechanically failed. This was not a new finding, since the aging problem of rubber-insulated wiring had already been documented as early as 1933 [22]. Statistically, what one would want to establish is whether the age of the electrical wiring in a building does or does not correlate with incidence of electrical fires. This question was raised in a 2005 New Zealand study [23], but the results were inconclusive. Much earlier, a British study [24] found that in the pre-World-War-II era there was a statistical correlation between incidence of electrical fires and age of wiring. This supports the conclusions concerning rubber-insulated wiring in UL's recent study, but does not help in gaining insights on the performance of thermoplastic-insulated wiring.

CPSC's results in Table 4 give a specific percent value to aging as a causative factor, but it is difficult to believe that this assignment is reliable. It would not be too difficult to mount a good statistics-based study, 
i.e., fire incidence vs. age of wiring. But, given a particular structure fire, it is exceptionally difficult to allocate the fire's cause to "deterioration due to aging." This is because aging does not cause a fire directly, whereas for indirect causation there can be numerous pathways. Causative factors such as "improper alterations" can be readily assessed, if evidence has been carefully preserved, but deterioration due to aging, can, in principle, affect every one of the physical mechanisms leading to an electrical fire, and even affect a single mechanism in multiple ways. Thus, it would be extraordinarily difficult to determine that aging was the causative factor leading to a particular fire. If one encounters insulation that is cracked, split or crumbled, for example, concerns may be raised as to an overt hazard of fire. A NIST study [25] demonstrated that wiring subjected to extreme overtemperature conditions can lead to insulation getting embrittled, falling off, and creating an electrical short. This finding is not surprising, but there are no laboratory studies that have ever endeavored to simulate actual fire outbreak. Sandia National Laboratories conducted several studies [26-29] on aging of wiring in nuclear power plants, but their studies do not have a direct applicability to the civilian sector and, furthermore, the studies only examined electrical failure but not ignition of fire.

\section{METALLURGICAL ISSUES ASSOCIATED WITH ELECTRICAL FAILURES}

In the majority of fire cases, the original equipment is sufficiently burned by fire that no realistic electrical tests can be done. Instead, it is necessary to discover what did or did not happen primarily by metallurgical investigations. Here, the state of the art is so poor as to almost be non-existent. The only metallurgical aspect of the investigation of electrical fires that has received any serious enquiry has been the cause vs. victim question pertinent to arc beads. Quite a few researchers have investigated numerous proposals for assessing whether a particular arc bead could have been the cause of a fire, or was rather a victim thereof. Unfortunately, none of these proposals yielded a reliable technique [30]. But, apart from this singular question, the literature is almost entirely devoid of research papers dealing with the metallurgical examination of failed electrical devices.

\section{RESEARCH STILL NEEDED}

\section{Physical mechanisms}

Most of the physical mechanism for ignition from electrical current have received only limited, exploratory study, if any at all. Thus, the entire field could benefit from an across-the-board increase in research. But a few mechanisms are so important as to need a specific discussion. Perhaps the topmost issue which has received no useful study is the breakdown voltage of plastic insulation materials at sub-kV voltages. Even for the most common low-voltage insulator, PVC, there are no published data [14]. The situation is so poor here that even the functional form of the governing relation (electrode gap distance vs. breakdown voltage) is unclear. Another topic is also related to the breakdown voltage question. Some fires occur when heavy objects are unintentionally placed upon an electric cord or cable. The physical mechanism is understood to involve progressive creep, followed by dielectric breakdown. But there has never been a laboratory study to examine these details. In fact, the whole topic of ignition due to dielectric breakdown in solid insulators needs to be studied. There is a plethora of papers on theoretical and experimental aspects of the breakdown of solid insulation, but almost none of these examine the ignition potential of such failures.

Non-ignitions from electric arcs have also received no study. This perhaps should be studied in a broader context, since non-ignitions in the presence of very high heat fluxes can involve other sources of heat, not just electricity. There have been a few theoretical investigations of this phenomenon, but these have not led to practical insights, so research is still wanting, but it could be structured with a more general scope. There is a related phenomenon which has also not received adequate study. Flaming sometimes occurs only while a heat source is applied, but ceases upon the removal of the heat source. This is a well-known phenomenon, but lacking good research.

\section{Minimum values}

A question often asked is: Are there voltage, current, or power minimums that must be exceeded for an electrical fire to occur? This is an important question, but there has been no focused research on this, despite the fact that standards organizations typically describe 'limited-power' circuits that are said to be less prone to fires. In the absence of concerted research, however, it is useful to consider the levels at which ignition has been documented. This depends, of course, on the fuel that is to be ignited, with gases being easiest ignitable, dust clouds less so, and solids less yet. Nonetheless, the reported minimums are small 
indeed [3]. Gases have been ignited by breaking a 1-watt incandescent bulb, while breaking a $3 \mathrm{~W}$ bulb has sufficed for causing a dust cloud explosion. Bedding had been ignited from a $6 \mathrm{~W}$ nightlight. By contrast, regulations typically envision 15 or $30 \mathrm{~W}$ as the power level below which hazard is deemed low. Gases have been ignited from a $0.5 \mathrm{~V}$ power supply that had inductive characteristics, while a man's pocket has been ignited by the shorting of a $1.2 \mathrm{~V} \mathrm{Ni-Cd}$ cell. Arc tracking has been a serious cause of fires in nominal 12 -volt (these operate typically at $14 \mathrm{~V}$ ) automotive wiring systems, although it has been noted in $6-\mathrm{V}$ systems also.

\section{Time frame for ignition}

An area where there has been no research whatsoever is in establishing a time frame for ignition. In some cases, this is a moot point. If a fire occurs due to an electrician fumbling while doing work on a live 480volt circuit, the effect is essentially instantaneous and no study of the time element is needed. But in other cases, research on the time element would be valuable. This is especially true in the area of poor connections and arcing across a carbonized path. Both of these phenomena normally involve long gestation periods, yet no methods exist for estimating this time period.

\section{Industrial fires}

Research on electrical fires associated with medium- and high-voltage circuits has been very sparse, and even on $480 \mathrm{VAC}$ industrial circuits. A number of authors have studied transformer explosions, manhole explosions, and conductor clashing [3]. But apart from these few topics, there has been little research. Several publications [31][32][33] focus on electrical accidents. While most of the work reported is these is on electric-shock injuries, they do also provide some illustrative case histories on industrial fires, but no actual laboratory research.

\section{Research to support codes and standards}

The objective of electrical codes, e.g., the NEC [34] in the US, is primarily to minimize the risk of electrocution, but there is a secondary objective of minimizing risk of fire. Countless textbooks and articles have been published giving background information or tutorials on the NEC. But it is striking to consider that there is essentially no research that has been published that directly compares fire hazard or fire risk for Code-complying electrical installations, versus ones that are either non-complying, or only complied with an earlier version before the Code was "improved" in some particular aspect.

The Codes, in turn, depend on product standards to ensure that testing of electrotechnical products is done in a reliable manner. Here, the situation is equally unsatisfactory. There are only two major organizations producing such standards: UL and IEC. Each of these organizations publishes hundreds of standards governing the performance and testing of electrotechnical products. In order that an engineering standard be competent, it is normally required that a research effort be mounted. Yet, neither of these organizations has been publishing papers to document what, if any, research was performed to establish their standards. This is an exceedingly unsatisfactory state of affairs and leads one to conclude that the standards were either developed without the benefit of any research, or that the research was so poor as to not warrant publication. A recent paper by this author [35] examined in detail several UL and IEC standards and the conclusions did not support the notion that these standards are satisfactory.

A specific concern already addressed earlier is the fact that the insulation temperature classes used by UL and IEC were established more than half a century ago and that there are reasons to believe that the classification procedures are poor and that the ratings are unreliable. The occurrence of electrical fires will be promoted if temperature classes are assigned which are optimistic.

\section{General research}

It is not ideal that the English-speaking world has had to depend so heavily in the electrical fires area on research published in Japanese. The publication of the Ignition Handbook was a unique opportunity to present some of the Japanese research to the Western world, but this does not solve the research problem on an ongoing basis. Furthermore, some aspects of electrical fires are locale-dependent or Code-specific and it is essential that a US research group be established that has an ongoing research mission in the electrical fires area. It is useful to consider that the Japanese effort was conducted primarily at an institution dedicated to forensic science research in general. This may be the best strategy in the US also. In addition, consideration should be given to fact that there is no agency in the US with a strong mission to conduct laboratory foren- 
sic science research of any kind; this situation should be remediated. Also, in view of the importance of metallurgical evidence, such research should not be restricted solely to electrical engineering, but should also include metallurgy pertinent to electrical fires.

\section{REFERENCES}

[1] Hall, J.R., private communication, National Fire Protection Assn., Quincy MA, 2007.

[2] Hall, J.R. jr., Bukowski, R.W., and Gomberg, A., "Analysis of Electrical Fire Investigations in Ten Cities,” National Bureau of Standards Report NBSIR 83-2803, Gaithersburg MD, 1983.

[3] Babrauskas, V., Ignition Handbook, Fire Science Publishers/Society of Fire Protection Engineers, Issaquah WA, 2003.

[4] The Authoritative Dictionary of IEEE Standard Terms (IEEE 100), $7^{\text {th }}$ ed., IEEE Press, New York, 2000.

[5] Kawase, T., (1975) The Breeding Process of $\mathrm{Cu}_{2} \mathrm{O}$, IAEI News 47:24-25 July/Aug.; (1977) Second Report, 49:45-46, Nov./Dec.

[6] Shea, J.J., "Identifying Causes for Certain Types of Electrically Initiated Fires in Residential Circuits," Aged Wiring Conf., Fire Protection Research Foundation, Quincy MA, 2006.

[7] Vieweg, R., ed., Elektrotechnische Isolierstoffe, Julius Springer, Berlin, 1937.

[8] "Tentative Method of Test for High-Voltage, Low-Current Arc Resistance of Solid Electrical Insulating Materials," American Society for Testing and Materials Standard ASTM D 495-48T, Philadelphia PA, 1948.

[9] "Method for the Determination of the Proof Tracking and Comparative Tracking Indices of Solid Insulating Materials," International Electrotechnical Commission Standard IEC 60112, Geneva.

[10] "Test Method for High-Voltage, Low-Current Dry Arc Resistance of Solid Electrical Insulation," ASTM International Standard ASTM D 495, West Conshohocken PA.

[11] Goodson, M., Perryman, T., and Colwell, K., (2002) Effects of Polyurethane Foam Systems on Wiring Ampacity, Fire \& Arson Investigator 52(4): 47-50, July.

[12] Hagimoto, Y., Watanabe, N., and Okamoto, K., "A Short Circuit as an Ignition Source of Fire," in Interflam 2007, Interscience Communications Ltd, London, 2007, pp. 1555-1560.

[13] Smith, L. E., and McCoskrie, D., (1990) What Causes Wiring Fires in Residences, Fire J. 84:1924, $69 \mathrm{Jan} / \mathrm{Feb}$.

[14] Babrauskas, V., (2006) Mechanisms and Modes for Ignition of Low-voltage, PVC-insulated Electrotechnical Products, Fire \& Materials 30:150-174, 2006, doi:10.1002/fam.900.

[15] Martzloff, F.D., “A Guideline on Surge Voltages in AC Power Circuits Rated up to 600 V," Proc. $3^{\text {rd }}$ Intl. Symp. on Electromagnetic Compatibility, Rotterdam, 1979, pp. 449-454.

[16] Martzloff, F.D., and Hahn, G.J., (1970) Surge Voltages in Residential and Industrial Power Circuits, IEEE Trans. on Power Apparatus and Systems PAS-89:1049-1056, doi:10.1109/TPAS.1970.292693.

[17] Dakin, T.W., (1948) Electrical Insulation Breakdown Treated as a Chemical Rate Phenomenon, Trans. AIEE 67:113-122.

[18] "Polymeric Materials - Long Term Property Evaluation," Underwriters Laboratories Inc. Standard UL 746B, Northbrook IL, 2000.

[19] Stricker, S., "Thermal Design of PVC-Insulated Heating Cable," Ontario Hydro Report 74-26-K, Toronto, 1974. 
[20] Aged Electrical Systems Research Application Symp., Fire Protection Research Foundation, Quincy MA, 2006.

[21] Dini, D.A., Fabian, T.Z., and Chapin, J.T., "An Analytical Study of Some Physical Properties of Wire and Cable Samples Collected from Older Homes," Aged Electrical Systems Research Application Symp., Fire Protection Research Foundation, Quincy MA, 2006.

[22] Morgan, P.D., Taylor, H.C., and Lethersich, W., (1933) The Heating of Domestic Pendant Lighting Fittings and their Connecting Leads, J. IEE 73:545-568.

[23] Patel, V., "Electrical Wiring Systems and Fire Risk in Residential Dwellings," Ministry of Economic Development report, Wellington, New Zealand, 2005.

[24] Gosland, L., (1956) Age and the Incidence of Fires in Electrical Installations, Proc. IEE 103A:271-284.

[25] Fulcomer, P.M., "Temperature Measurement on Operating Surface Mounted Lighting Fixtures," National Bureau of Standards Report NBSIR 79-1912, Gaithersburg MD, 1979.

[26] Chavez, J.M., "Steady-State Environment Cable Damage Testing," Sandia National Laboratories Quick Look Test Report, Albuquerque NM, 1984.

[27] Lukens, L.L., "Nuclear Power Plant Electrical Cable Damageability Experiments," Sandia National Laboratories Report SAND82-0236, Albuquerque NM, 1982.

[28] Jacobus, M.J., and Fuehrer, G.F., "Submergence and High Temperature Steam Testing of Class 1E Electrical Cables," Sandia National Laboratories Report SAND90-2629; NUREG/CR-5655, Albuquerque NM, 1991.

[29] Nowlen, S.P., "An Investigation of the Effects of Thermal Aging on the Fire Damageability of Electric Cables," Sandia National Laboratories Report SAND90-0696; NUREG/CR-5546, Albuquerque NM, 1991.

[30] Babrauskas, V., (2004) Arc Beads from Fires: Can 'Cause' Beads Be Distinguished from 'Victim' Beads by Physical or Chemical Testing? J. Fire Protection Engineering 14:125-147, doi:10.1177/1042391504036450.

[31] Mazer, W.M., Electrical Accident Investigation Handbook, 3 vols., Electrodata, Inc., Glen Echo $\mathrm{MD}$, various dates).

[32] Nabours, R.E., Fish, R.M., and Hill, P.F., Electrical Injuries: Engineering, Medical and Legal Aspects, $2^{\text {nd }}$ ed., Lawyers \& Judges Publishing Co., 2004.

[33] EC\&M (Electrical Construction \& Maintenance) magazine, Penton Media, Chicago (various issues).

[34] "National Electrical Code" National Fire Protection Assn. NFPA 70, Quincy, MA.

[35] Babrauskas, V., and Simonson, M., (2007) Fire Behaviour of Plastic Parts in Electrical Appliances-Standards versus Required Fire Safety Objectives, Fire \& Materials 31:83-96, doi:10.1002/fam.927. 